\title{
Síndrome de Alpers uma variante da Doença de Creutzfeldt-Jakob?
}

\author{
Alpers' disease a variant of Creutzfeldt-Jakob Disease?
}

\section{Henrique Pott Jr. ${ }^{1}$, Maria Cristina Furian Ferreira ${ }^{2}$, Amilcar Castro de Mattos $^{3}$}

\begin{abstract}
RESUMO
A síndrome demencial, geralmente está associada a outras anomalias neurológicas, sendo que o diagnóstico definitivo da maioria das síndromes depende do exame neuropatológico. A doença de Creutzfel$\mathrm{dt}$-Jakob em crianças apresenta exame neuropatológico semelhante à Síndrome de Alpers, o que têm atribuído atenção ao diagnóstico diferencial entre estas síndromes clínicas. O objetivo deste estudo foi relatar um caso de encefalopatia degenerativa espongiforme progressive na infância com estudo de necrópsia.
\end{abstract}

Unitermos. Demência, Diagnóstico Diferencial, Síndrome de Creutzfeldt-Jakob, Síndrome de Alpers.

Citaçáo. Pott Jr. H, Ferreira MCF, Mattos AC. Síndrome de Alpers uma variante da Doença de Creutzfeldt-Jakob?

Trabalho realizado na Pontifícia Universidade Católica de Campinas, Campinas-SP, Brasil.

1. Médico Residente, Hospital São Paulo, Universidade Federal de São Paulo. Sáo Paulo, Brasil.

2. Patologista, Docente da Disciplina de Patologia, Faculdade de Medicina, Centro Ciências da Vida, Pontifícia Universidade Católica de Campinas.Campinas, SP, Brasil.

3. Patologista, Hospital e Maternidade Celso Pierro da PUC-Campinas e Hospital das Clínicas da Unicamp, Campinas, SP, Brasil.

\section{ABSTRACT}

The dementia, is usually associated with other neurological abnormalities, and a definitive diagnosis of most syndromes depends on neuropathological examination. Creutzfeldt-Jakob disease in children presents neuropathological examination similar to Alpers' disease, which have given attention to the differential diagnosis between these syndromes. The aim of this study was to report a case of progressive degenerative spongiform encephalopathy in infancy with study of autopsy.

Keywords. Dementia, Differential Diagnosis, Creutzfeldt-Jakob Syndrome, Alpers Syndrome.

Citation. Pott Jr. H, Ferreira MCF, Mattos AC. Alpers' disease a variant of Creutzfeldt-Jakob Disease? 


\section{INTRODUÇÃO}

Síndrome demencial é um termo genérico que descreve a disfunção crônica ou progressiva das funçôes corticais e subcorticais, que resulta em um complexo declínio cognitivo ${ }^{1}$. Praticamente todas as doenças neurodegenerativas envolvem o processamento anormal de proteínas neuronais. Os príons são proteínas infecciosas, e as doenças priônicas, ou encefalopatias espongiformes transmissíveis, são um grupo de doenças neurodegenerativas determinadas pelo acúmulo de príons, que afetam os seres humanos e animais, e que cursam com síndrome demencial ${ }^{2}$.

As doenças priônicas humanas têm sido tradicionalmente classificadas em doença de Creutzfeldt-Jakob (DCJ), doença de Gerstmann-Straussler-Scheinker e Kuru, e podem ser divididas em três categorias etiológicas: esporádica, adquirida e herdada. As doenças priônicas adquiridas incluem DCJ iatrogênica, kuru, e resultar de uma exposição acidental a prions humanos através de procedimentos médico-cirúrgicos ou a participação em canibalismo. DCJ esporádica ocorre em todos os países, com uma distribuição aleatória e incidência anual de um caso para cada um milhão de pessoas ${ }^{1,2}$. As doenças priônicas herdadas podem ser diagnosticadas pela análise do gene da proteína priônica (prion protein gene - RPPN), e a utilização destes marcadores genéticos de diagnóstico definitivo permitiu o reconhecimento de um amplo espectro fenotípico da doença priônica humana, que inclui uma gama de demências atípicas e a insônia familiar fatal ${ }^{2}$.

Uma vez que a deterioração neurológica em crianças é causada por uma complexa série de distúrbios neurológicos degenerativos que cursam com alteraçôes espongiformes, atualmente ainda há a preocupação de que uma variante da doença de Creutzfeldt-Jakob (vDCJ) em crianças pode ser diagnosticada como Síndrome de Alpers $(\mathrm{SA})^{3}$. Tal questionamento fundamenta-se na semelhança de achados neuropatológicos entre as duas doenças ${ }^{4}$, e no relato de que uma encefalopatia espongiforme foi reproduzida em hamsters após a inoculação do tecido cerebral de uma criança com síndrome de Alpers 5 .

Sendo assim, o objetivo deste estudo foi descrever um caso raro de paciente portadora de atrofia encefálica, de distúrbio grave e progressivo, com alteraçôes cerebrais e cerebelares degenerativas, com lesôes espongiformes e hipoplasia neuronal. Por intermédio da realização da necropsia, buscamos correlacionar todo o quadro clínico e confrontar as alteraçóes estruturais encontradas com as descritas na literatura.

\section{Descriçáo do caso}

Paciente do sexo feminino, 5 anos, com quadro clínico de encefalopatia progressiva e internada em nosso hospital desde os 6 meses de idade. Como apresentava insuficiência respiratória, foi mantida em respiração assistida desde esta data. Dados clínicos do início da internação excluem a possibilidade de doença isquêmica secundária a traumatismo durante o período de parto. A piora progressiva dos reflexos neurológicos, profundos inclusive, levou a sucessivas investigaçóes clinico-laboratoriais pouco elucidativas.

O projeto foi submetido ao Comitê de Ética em Pesquisa da Pontifícia Universidade Católica de Campinas com protocolo número 0272/11.

\section{DISCUSSÃO}

$\mathrm{O}$ acúmulo de proteínas neuronais morfologicamente alteradas é uma característica comum subjacente à patogênese de doenças neurodegenerativas que manifestam-se clinicamente sob a forma de síndrome demencial como a doença de Alzheimer e as doenças de príon.

O mecanismo de processamento anormal de proteínas neuronais pode acarretar em dobramento inadequado de proteínas, modificaçôes pós-traducionais de proteínas recém-sintetizadas, clivagem proteolítica anormal, splicing de gene anômalo, expressão inadequada, ou clearance diminuído de proteína degradada ${ }^{2}$.

As proteínas processadas inadequadamente muitas vezes se acumulam porque os mecanismos celulares para removê-los são ineficazes. Assim, à medida que o número de proteínas defeituosas aumenta, por conta do crescimento geométrico, cresce a quantidade de proteínas defeituosas nas células cerebrais afetadas. $\mathrm{O}$ acúmulo celular de proteínas defeituosas determina o mau funcionamento de conjuntos distintos de neurônios, causa a morte das células afetadas e, portanto, de acordo com a área neurológica afetada as manifestações clínicas da doença ${ }^{1,2,6,7}$.

Não obstante, defeitos mitocondriais ocorrem em 
uma ampla variedade de doenças neurológicas degenerativas, e determinam as doenças causadas pela função anormal da mitocôndria como um importante diagnóstico diferencial com as doenças neurodegenerativas causadas pelo acúmulo de proteínas defeituosas, durante a abordagem da síndrome demencial, em especial quando se tratar de pacientes jovens ${ }^{8}$.

As doenças mitocondriais (DMt) abrangem um grupo heterogêneo de distúrbios nos quais a diminuição da cadeia respiratória mitocondrial está presente ${ }^{8}$. O resultado final do dano sob a cadeia respiratória é a disfunção na produção de ATP. Portanto, tecidos tendo uma alta taxa de consumo de energia ou uma baixa taxa de mitose, ou seja, músculo esquelético e sistema nervoso central, são particularmente afetados ${ }^{8}$.

A etiopatogênese do dano neuronal promovido pela disfunção mitocondrial fundamenta-se na interação entre os fatores pro-apoptoticos e anti-apoptoticos da família BCL2. A caspase 9 regula esta via, e é ativada depois de sensores intracelulares indicam dano celular irreversível. Os deflagradores da via apoptótica mitocondrial incluem o aumento intracelular de espécies reativas de oxigênio, danos no DNA, a resposta a proteínas desdobradas, e a privação de fatores de crescimento. Estes iniciadores levam a abertura do poro de transição da permeabilidade mitocondrial (PTPmt) determinando aumento da permeabilidade da mitocôndria, e promovendo a liberação de proteínas pro-apoptoticas (por exemplo, o citocromo c) a partir do espaço intermitochondrial membrana no citosol$^{9}$. Em última análise, a presença das proteínas proapoptoticas determina a morte celular por meio da clivagem de inúmeras proteínas celulares e ativação Dnases.

Por conta da semelhança de achados neuropatológicos, e do relato de que uma encefalopatia espongiforme foi reproduzida em hamsters após a inoculação do tecido cerebral de uma criança com síndrome de Alpers, ainda há a preocupação de que uma variante da doença priônica de Creutzfeldt-Jakob em crianças pode ser diagnosticada como uma doença mitocondrial, em especial a Síndrome de Alpers. Não obstante, em 1996, o United Kingdom National Creutzfeldt-Jakob Disease Surveillance Unit (UK-NCJDSU) reconheceu a existência de uma nova variante da DCJ. Ela foi chamada de Nova Variante da Doença de Creutzfeldt-Jakob. Distingue-se da forma clássica porque atinge pacientes muito mais jovens, normalmente em torno de vinte anos, pela ocorrência, no início da síndrome, de sintomas sensoriais e psiquiátricos, e pela ausência das características típicas do eletroencefalograma da $\mathrm{DCJ}^{10}$. O diagnóstico definitivo da doença de Creutzfeldt-Jakob tem sido baseada na apresentação clínica e confirmado pela identificação no tecido cerebral de degeneração espongiforme, perda neuronal, e astrogliose $^{2,6,7}$. O diagnóstico foi facilitado pela capacidade de identificar isoforma patológica $\left(\mathrm{PrP}^{\mathrm{CJD}}\right)$ da proteína priônica $\left(\mathrm{PrP}^{\mathrm{c}}\right)$, uma proteína celular normal, em imunoblots de tecido cerebral não fixado ou em tecido cerebral fixado em formol e em blocos de parafina ${ }^{2,6}$. Ainda, o diagnóstico imunológico da doença de Creutzfeldt-Jakob pode ser feito com o uso de anticorpos que reconhecem as isoformas normal e patológica da proteína $\mathrm{PRP}^{2,6}$.

Por outro lado, o diagnóstico de DMt depende da associação de dados clínicos, químicos, eletrofisiológicos, bioquímicos, histológicos ou investigaçóes genéticas. $\mathrm{O}$ índice da suspeita para uma doença mitocondrial deve ser alta se houver o envolvimento sintomático e aparentemente não relacionado em dois ou mais tecidos. Para o diagnóstico definitivo das doenças mitocondriais, testes bioquímicas ou genéticos moleculares são necessários. Geralmente, os testes genéticos dependem da apresentação clínica e características da herança ${ }^{11}$. A degeneração neuronal progressiva da infância com doença hepática, a Síndrome de Alpers, é uma doença mitocondrial fatal da infância, que geralmente apresenta-se como atraso de desenvolvimento, deterioração visual, início súbito de crises convulsivas intratáveis e disfunção hepática. Histopatologicamente é caracterizada por espongiose do córtex cerebral, especialmente dos lobos occipital, e núcleos da base, associado a perda neuronal e gliose ${ }^{11}$.

Durante a necrópsia do caso apresentado anteriormente, foi notada atrofia cerebral global, sendo mais pronunciada em hemisfério direito, com retração intensa dos giros e sulcos. (Figura 1) As meninges se mostravam espessadas, e em algumas áreas intensamente aderidas; o cerebelo apresentava impressões semelhantes a herniaçóes bilaterais. Foram retiradas as raízes nervosas dorsais em regiôes cervicais, torácicas e lombares, bilateralmente.

Não haviam anormalidades significativamente graves em outros órgãos, sendo que o pulmão apresen- 


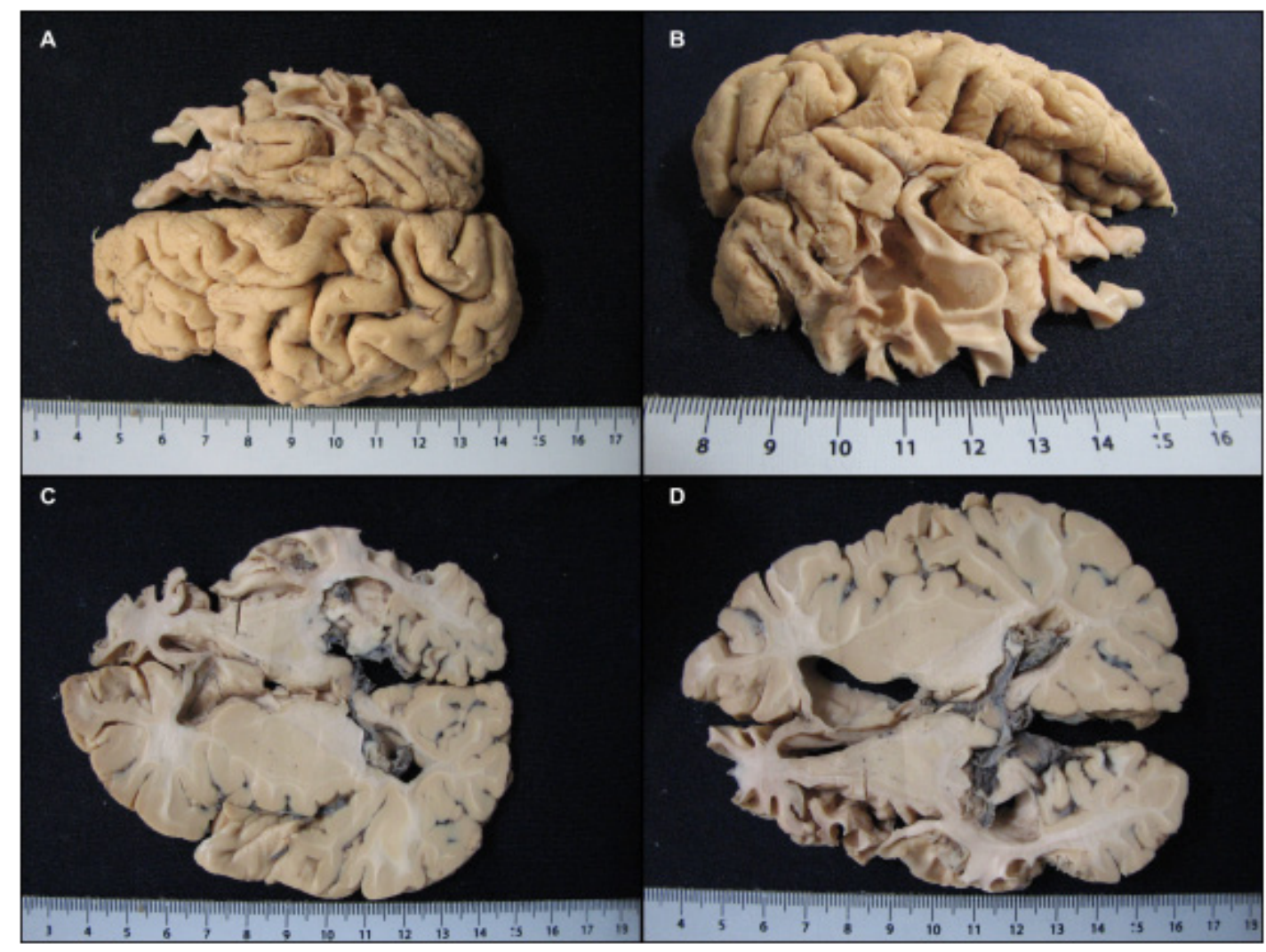

Figura 1. Macroscopia evidenciando atrofia cerebral global, sendo mais pronunciada em hemisfério direito, com retração intensa dos giros e sulcos (A e B). Corte tomográfico do cérebro fixado mostrando a intensa diminuição de substância branca (C e D).

tava áreas múltiplas e focais de fibrose além de dilatação leve do ventrículo direito cardíaco, sugerindo algum grau de repercussão hemodinâmica. Haviam lesões cutâneas papulares, com discreta hipercromia, esparsas pela região tóraco-abdominal.

O exame microscópico revelou a presença de atrofia do arcabouço cerebral, com hipoplasia neuronal, múltiplas lesões espongiformes com eventual aspecto microcístico em cérebro e cerebelo, em múltiplas diferentes áreas, afetando todos os lobos cerebrais e também de gânglios da base, sendo estas lesões mais proeminentes em hemisfério direito. Em cerebelo, as alteraçóes espongiformes também foram encontradas, porém em menor intensidade e de modo mais difuso. As raí- zes nervosas dorsais não mostraram sinais de degeneração ou inflamação nítidas (Figura 2).

A musculatura voluntária de cinturas escapular e pélvica, além de musculaturas intercostal, cervical e abdominal, exibia apenas discreta atrofia. As lesóes de pele revelaram hiperceratose ortoceratótica, infiltrado inflamatório liquenóide, moderado, multifocal, não-leucocitoclástico, atingindo a interface derme-epiderme de modo

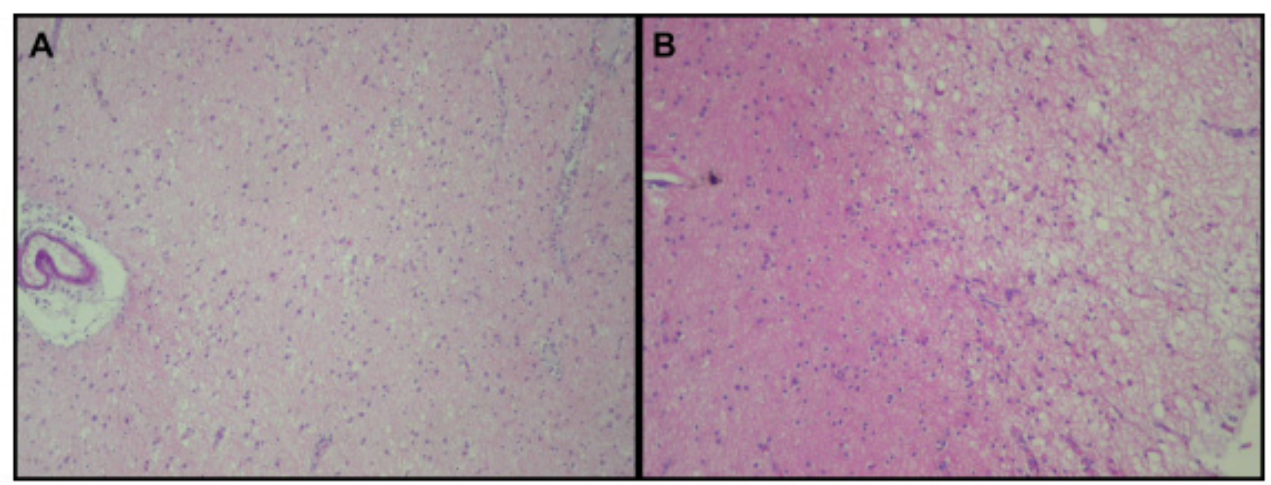

Figura 2. Microscopia óptica mostrando na panorâmica (A) e em pormenor (B) as alteraçóes degenerativas de padrão espongiforme. 
esporádico. Pulmóes revelavam fibrose com hiperplasia de histiócitos, sem sinais de inflamação pulmonar recente significativa.

Tanto a análise anatomopatológica quanto histopatológica do tecido cerebral com a identificação de degeneração espongiforme, perda neuronal e astrogliose, achados que habitualmente são referidos como patognomônicos da DCJ, sugeriram o diagnóstico de doença de Creutzfeldt-Jakob, e restando a definição etiológica em esporádica ou herdada.

Todavia, considerando a faixa etária infantil, evolução e manifestações clínicas, alterações morfológicas, e as áreas afetadas, o diagnóstico de Síndrome de Alpers parece ser a melhor possibilidade diagnóstica para o caso apresentado, apesar da ausência de lesôes hepáticas características.

A dificuldade de se estabelecer um diagnóstico definitivo permite ainda a possibilidade de concomitância destes dois mecanismos etiopatogênicos, o que tornaria este o primeiro caso relatado na literatura brasileira. Contudo, parece improvável que os dois mecanismos etiopatogênicos concorram simultaneamente.

De fato, este caso ilustra a dificuldade de se estabelecer um diagnóstico definitivo entre estas síndromes clínicas, e aponta que, apesar de na grande maioria dos casos a manifestaçóes clínico-laboratoriais e morfológicas permitirem um diagnóstico aproximado, exames complementares de maior complexidade são necessários para a definição etiológica precisa. Ele ilustra ainda a semelhança entre os achados neuropatológicos que fundamenta a existente preocupação de que uma variante da doença priônica de Creutzfeldt-Jakob em crianças pode ser diagnosticada como uma doença mitocondrial, em especial a Síndrome de Alpers.

\section{CONCLUSÃO}

Apesar de na grande maioria dos casos a manifestações clínicas correlacionadas às alteraçóes morfológicas permitirem um diagnóstico aproximado, o diagnóstico etiológico definitivo para as síndromes de encefalopatia espongiforme ainda é dificil e dependente de exames complementares de maior complexidade.
Além disso, os achados neuropatológicos semelhantes, a despeito da etiopatogenia distinta, fundamentam a existente preocupação de que uma variante da doença priônica de Creutzfeldt-Jakob em crianças pode ser diagnosticada como uma doença mitocondrial, em especial a Síndrome de Alpers.

Desta maneira, torna-se necessário a pesquisa, e comparação de métodos diagnósticos alternativos que incrementem a sensibilidade e especificidade, para orientar melhor o diagnóstico definitivo, e afastar ou confirmar tal preocupação.

\section{REFERÊNCIAS}

1.Ritchie K, Lovestone S. The dementias. Lancet 2002;360:1759-66. http://dx.doi.org/10.1016/S0140-6736(02)11667-9

2.Johnson RT. Prion diseases. Lancet Neurol 2005;4:635-42.

http://dx.doi.org/10.1016/S1474-4422(05)70192-7

3.te Water Naudé J, Verity CM, Will RG, Devereux G, Stellitano L. Is variant Creutzfeldt-Jakob disease in young children misdiagnosed as Alpers' syndrome? An analysis of a national surveillance study. J Neurol Neurosurg Psychiatry 2004;75:910-3.

http://dx.doi.org/10.1136/jnnp.2003.015651

4.Crompton MR. Alpers' disease -- a variant of Creutzfeldt-Jakob disease and subacute spongiform encephalopathy? Acta Neuropathol 1968;10:99-104.

http://dx.doi.org/10.1007/BF00691303

5.Manuelidis EE, Rorke LB. Transmission of Alpers' disease (chronic progressive encephalopathy) produces experimental Creutzfeldt-Jakob disease in hamsters. Neurology 1989;39:615-21.

6.Beckham JD, Tyler KL. Infectious disease - developments in the field of Creutzfeldt-Jakob disease. Rev Neurol Dis 2007;4:168-72.

7.Mead S, Whitfield J, Poulter M, Shah P, Uphill J, Campbell T, et al. A novel protective prion protein variant that colocalizes with kuru exposure. N Engl J Med 2009;361:2056-65.

http://dx.doi.org/10.1056/NEJMoa0809716

8.Filosto M, Tomelleri G, Tonin P, Scarpelli M, Vattemi G, Rizzuto N, et al. Neuropathology of mitochondrial diseases. Biosci Rep 2007;27:23-30.

http://dx.doi.org/10.1007/s10540-007-9034-3

9.Hotchkiss RS, Strasser A, McDunn JE, Swanson PE. Cell death. N Engl J Med 2009;361:1570-83.

http://dx.doi.org/10.1056/NEJMra0901217

10.Will RG, Ironside JW, Zeidler M, Cousens SN, Estibeiro K, Alperovitch A, et al. A new variant of Creutzfeldt-Jakob disease in the UK. Lancet 1996;347:921-5.

http://dx.doi.org/10.1016/S0140-6736(96)91412-9

11.Finsterer J. Mitochondrial disorders, cognitive impairment and dementia. J Neurol Sci 2009;283:143-8.

http://dx.doi.org/10.1016/j.jns.2009.02.347

http://dx.doi.org/10.1016/j.jns.2009.02.009 